\title{
Immunological mechanisms in pleural disease
}

\author{
V.B. Antony
}

\begin{abstract}
Immunological mechanisms in pleural disease. V.B. Antony. (C) ERS Journals Ltd 2003. ABSTRACT: The pleural membrane consisting of pleural mesothelial cells and its underlying connective tissue layers play a critical role in immunological responses in both local and systemic diseases. The pleura, because of its intimate proximity to the lung, is positioned to respond to inflammatory changes in the lung parenchyma. Importantly, several systemic diseases have a predilection for expression on the pleural surface.

Immunological responses in the pleura include the development of pleural permeability and pleural effusion formation as well as the development of pleural fibrosis and scarring. Under either circumstance, the normal functioning of the pleura is impaired and has multiple consequences leading to increased morbidity and even mortality for the patient.

During infections in the pleural space, the pleural mesothelium responds by actively recruiting inflammatory phagocytic cells and allowing the movement of proteins from the vascular compartment into the pleural space. The release of chemokines by the pleural mesothelium allows for directed migration of phagocytic cells from the basilar surface of the pleura towards the apical surface.

In malignant disease, the pleura may be the site of primary tumours such as mesothelioma and also the site for malignant metastatic deposits. Certain cancers such as cancers of the breast, ovary, lung, and stomach have a predilection for the pleural mesothelium. The process whereby malignant cells attach to the pleural mesothelium and develop autocrine mechanisms for survival in the pleural space are elucidated in this review. The pleura functions not only as a mechanical barrier, but also as an immunologically and metabolically responsive membrane that is involved in maintaining a dynamic homeostasis in the pleural space.

Eur Respir J 2003; 21: 539-544.
\end{abstract}

Correspondence: V.B. Antony, Indiana University School of Medicine, Pulmonary and Critical Care Medicine, RL Roudebush VA Medical Center, 1481 West 10th Street, Indianapolis, IN 46202, 317/554-0036, USA.

Fax: 3175540262

E-mail: vantony@iupui.edu

Keywords: Chemokines

cytokines

inflammation

malignancy

mesothelial cell

Received: April 122002

Accepted after revision: April 302002

This study was supported by National Institutes of Health grants R01 A141877, R01 A137454, and R01 A145338.
The pleura is a dynamic, metabolically active membrane that is involved both in maintaining homeostasis as well as in responses to pleural inflammation. The pleural membrane, by expressing certain proteins on its surface and its plasticity, is involved during the quiescent and normal functioning of the mesothelium. Perturbation of the homeostatic balance causes a remarkable and abrupt change in the mesothelium. The pleural mesothelial cell is an active participant in the immunological responses and orchestrates a cascade of events that are aimed at eliminating the antigen and maintaining normal pleural function. Some of the responses will be described below.

\section{Pleural anatomy}

The pleura encloses the chest cavity and is derived from the primitive mesoderm [1-3]. The thoracic cage has two separate individual pleural cavities which are also separated from the pericardial cavity. This arrangement allows flexibility as the organs grow or change in shape and form within the limited space of the thoracic cage. The pleural cavity is a closed space between the visceral and parietal pleura [4, 5]. Both the parietal and the visceral pleura are similar in mesodermal origin and have minor differences in anatomical structure. The pleura extends into the interlobar fissure and may, during inspiration, fill the pleural cavity to form recesses on the surface of the lung. The pleura is essential for the efficient functioning of the lung. It provides protection and allows for a smooth, lubricating, elastic surface for movement of the lung bellows during inspiration and expiration. The pleural mesothelium is lubricated by a small amount of pleural fluid and varies in thickness between different animal species. The most striking finding on examination of the pleural surface via

Previous articles in this series: No. 1: Baldacci S, Omenaas E, Oryszczyn MP. Allergy markers in respiratory epidemiology. Eur Respir $J$ 2001; 17: 773-790. No. 2: Antó JM, Vermeire P, Vestbo J, Sunyer J. Epidemiology of chronic obstructive pulmonary disease. Eur Respir J 2001; 17: 982-994. No. 3: Cuvelier A, Muir J-F. Noninvasive ventilation and obstructive lung diseases. Eur Respir J 2001; 17: 1271-1281. No. 4: Wysocki M, Antonelli M. Noninvasive mechanical ventilation in acute hypoxaemic respiratory failure. Eur Respir J 2001; 18: 209-220. No. 5: Østerlind K. Chemotherapy in small cell lung cancer. Eur Respir J2001; 18: 1026-1043. No. 6: Jaakkola MS. Environmental tobacco smoke and health in the elderly. Eur Respir J 2002; 19: 172-181. No. 7: Hollings N, Shaw P. Diagnostic imaging of lung cancer. Eur Respir J 2002; 19: $722-742$. No. 8: Künzli N. The public health relevance of air pollution abatement. Eur Respir J 2002; 20: 198-209. No. 9: D'Amato G, Liccardi G, D'Amato M, Cazzola M. Outdoor air pollution, climatic changes and allergic bronchial asthma. Eur Respir J 2002; 20: 763-776. No. 10: Pelosi P, Brazzi L, Gattinoni L. Prone position in acute respiratory distress syndrome. Eur Respir J 2002; 20: 1017-1028. No. 11: Sartori C, Matthay MA. Alveolar epithelial fluid transport in acute lung injury: new insights. Eur Respir J 2002; 20: 1299-1313. No. 12: Zocchi L. Physiology and pathophysiology of pleural fluid turnover. Eur Respir J 2002; 20: 1545-1558. 
microscopy are the number of microvilli [6-8]. The microvilli are $\sim 0.1 \mu \mathrm{M}$ in diameter and up to $\geqslant 3 \mu \mathrm{M}$ in length. They exist singly, but often group together. The density of the microvilli ranges between $100-600$ per 100 square microns. There is a higher density of microvilli on the visceral surface than on the parietal surface. There are anatomical variations of the pleura based upon the organ that it covers. For example on the visceral surface, the pleura is thin with flattened mesothelial cells and sparse microvilli. On the parietal surface, the pleura may be dense and fuse with the periosteum of the underlying rib. The normal amount of pleural fluid is $\sim 0.5-1 \mathrm{~mL}$ and contains $1-2 \mathrm{~g}$ of protein per $100 \mathrm{~mL}$ [9-11]. There are $\sim 1,500-4,500$ cells in $1 \mathrm{~mL}$ of pleural fluid. These are mononuclear cells with occasional lymphocytes. The mononuclear cells are mostly macrophagelike. The pleura is a monolayer of mesothelial cells, but also has several layers below the monolayer that include: 1) the basil lamina; 2) an elastic layer; 3) a loose connective tissue layer; 4) a deeper fibro-elastic layer.

The nerves, vessels, and lymphatics lie in the loose connective tissue layer. Thus, in disease states where there is inflammation of the pleura, cells have to traverse through the connective tissue layer into the basil lamina and out through the mesothelial surface into the pleural space. There are some well-documented communications between the pleural cavity and the lymphatics. These include stomas, membrana cribriformis, and lacunae [12-18].

\section{The pleural mesothelial cell}

The pleural mesothelial cell is a functionally dynamic cell which has an apical surface which is covered with microvilli and a defined basilar surface. Between the cells are apical-type junctions, adherins junctions, intermediate junctions, ZO-1 type junctions, and desmosomes [18]. On ultrastructrual evaluation of the mesothelial cell, it is found to contain both rough and smooth endoplasmic reticulum, mitochondria, as well as several membrane-bound micropinocytotic vesicles and larger vesicles [19]. The pleural mesothelial cell expresses epithelial keratins as well as vimentins [20-22]. The uptake of extracellular fluid by mesothelial cells is demonstrated by the pinocytosis of horseradish peroxidase and is both time and dose dependent. Large, solid particles are ingested by pleural mesothelial cells in culture. Crysotile asbestos fibres have been demonstrated to be taken up by parietal pleural mesothelial cells and are present in phagocytic vacuoles. Pleural mesothelial cells also ingest quartz, latex particles, mycobacteria, and bacteria. They synthesise macromolecules of connective tissue including collagen, elastin, and laminin. They are known to release oxygen radicals including long-acting forms of oxidant species. The collagens are a major component of the pleural extracellular matrix and comprise up to $80 \%$ of the extracellular pleural dry weight. Type-I as well as type-III collagen fibrils are found in pleural connective tissue. Pleural mesothelial cells also produce elastic fibres comprising of elastin microfibrils. Pleural mesothelial cells also produce proteoglycans, which are comprised of a protein core to which a large number of repeating carbohydrate chains are attached.

\section{Pleural permeability during inflammation}

Exudative pleural effusions with a high protein content remain one of the markers of pleural involvement in either a local or systemic disease [23]. During the process of inflammation, the leak of proteins across the pleural membrane breaches the integrity of the membrane [10]. During equilibrium, the small amount of protein in the pleural fluid is maintained via homeostatic mechanisms. To date, the hypothesis put forward for the mechanisms of exudative pleural fluid accumulation include increases in hydrostatic pressure, decreases in oncotic pressure, decreases in the pressure in the pleural space, and impaired lymphatic pleural fluid drainage from the pleural space. The pleural mesothelium, which is considered to be a simple membrane, has emerged as a dynamic cellular organ that is capable of pericellular permeability [24]. Mesothelial barrier dysfunction occurs during the process of inflammation. Changes in pleural permeability to proteins have been demonstrated with exposure of pleural mesothelial monolayers to lipopolysaccharide (LPS), thrombin, and bacteria [25, 26]. The interaction of the mesothelium with cytokines or bacteria can cause mesothelial cells to release vascular endothelial growth factor (VEGF) [27]. VEGF is a potent mediator of endothelial permeability [28]. It is a $35-43 \mathrm{kD}$ polypeptide expressed in several isoforms. It is also known as vascular permeability factor. It has been demonstrated to play a central role in the formation of ascites in animal models and has been found in high quantities in pleural effusions in patients with malignant disease or parapneumonic effusions. VEGF is one of the factors that have been shown to cause a change in pleural permeability to protein molecules.

\section{Cellular trafficking during inflammation}

Despite general agreement that the pleura, when inflamed, allows for direct participation of the mesothelial cell in pathogenesis of the effusion, there are very few studies that address the role of the mesothelial cell in cell trafficking into the pleural space. The primary or earliest events during pleural inflammation are mediated via the response of the mesothelial cell and secondarily by the recruited inflammatory cells in cytokines that are activated by the primary mesothelial responses. Acute inflammatory processes are associated with the development of an inflammatory cell rich pleural effusion. A migration of neutrophils followed by mononuclear phagocytes and lymphocytes is a characteristic feature of this inflammation. These inflammatory cells move from the vascular compartment into the pleural space. These phagocytic cells move from the basilar surface of the mesothelium that is covered by a capillary network towards the apical surface of the mesothelium. The sentinel role of the mesothelial cell in orchestrating this phenomenon is still being elucidated [29-32].

Mesothelial cells have been shown to express intercellular adhesion molecule (ICAM)-1. Following exposure to tumour necrosis factor (TNF)- $\alpha$ and interferon (IFN)- $\gamma$, these adhesion molecules allow for adherence of the neutrophils or monocyte to the mesothelial cell via the CD-11/CD-18 integrin on the phagocytic cell [33-36]. Expression of these adhesive glycoproteins by the mesothelial cell allow the phagocytic cell to migrate through the intercellular spaces into the pleural compartment.

Pleural mesothelial cells contain contractile actin filaments as shown by Rhodamine Phalloidin staining. Activation of mesothelial monolayers results in the development of intercellular gaps associated with architectural changes of the actin filaments and contraction of mesothelial cells. The appearance of intercellular gap formation is mediated via the cadherins (fig. 1) which are transmembrane intercellular connections between mesothelial cells at adherens junctions. The cadherins are a family of cell-adhesion receptors that are crucial for homophilic binding between mesothelial cells and 


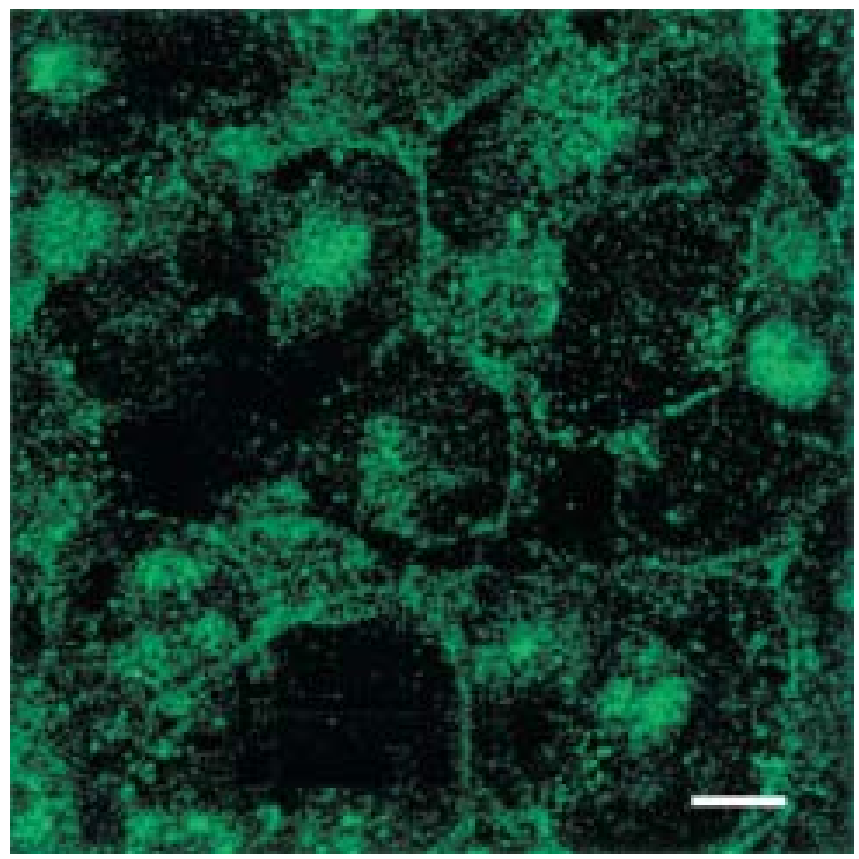

Fig. 1.- Pleural mesothelial cells stained for N-cadherin. Fluorescein

play an important role in cell morphology and permeability [37-39]. Cadherins are calcium dependent. They are linked to the actin filaments via catenins (fig. 2). Downregulation of these proteins is associated with increased pleural permeability to cells and protein. The cadherins were initially described on endothelial cells and include E-cadherin (epithelial cadherin), P-cadherin (placental cadherin), and $\mathrm{N}$-cadherin (neural cadherin). Mesothelial cells express all three cadherins. The phenomenon of opening up of adherens junctions between pleural mesothelial cells is reversible with mesothelial cells returning to their normal shape with closure of junctions within $15 \mathrm{~min}$ in vitro when stimulated. Thus, adherens junctions function as "zippers" between mesothelial cells. The transfer of neutrophils across mesothelial monolayers

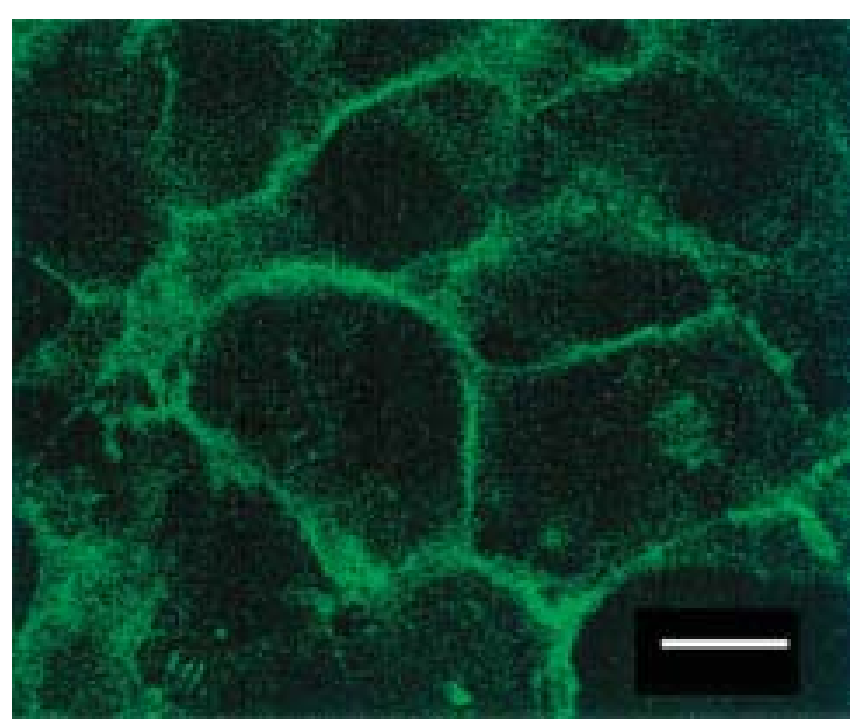

Fig. 2.-Pleural mesothelial cells stained for $\beta$-catenins. Fluorescein isothiocyanate labelled. Zeiss-confocal microscope. Internal scale bar $=5$ microns. is associated with a drop in electrical resistance across the pleural membrane.

\section{The mesothelium in infectious diseases}

The pleural mesothelial cell is responsible, in part, for the accumulation of neutrophils and mononuclear phagocytes in the pleural space. A recently described chemotactic-cytokine family, called the chemokine family [32] which is made up of three closely related polypeptide subfamilies has been described in pleural mesothelial cells. These subfamilies are generically known as the chemokine family and include the $\mathrm{C}-\mathrm{X}-\mathrm{C}$ chemokines, the $\mathrm{C}-\mathrm{C}$ chemokines, or a $\mathrm{C}$ chemokine known as lymphotactin. Chemokines are $7-10 \mathrm{kD}$ are heparin-binding proteins. Mesothelial cells release interleukin (IL)-8 which is a member of the C-X-C chemotacticchemokine family. IL-8 has been found in significant quantities in pleural fluids obtained from patients who develop parapneumonic effusions and is found in higher concentrations in empyema pleural fluid than in those with uncomplicated parapneumonic effusions [35]. Inhibition of IL-8 released by mesothelial cells inhibits neutrophil chemotaxis in a chemotactic Boyden Chamber assay. There is significant correlation between the amount of IL-8 and the number of neutrophils in empyema fluid. IL-8 inhibited neutrophil entry by $80 \%$ in vivo in a rabbit model of endotoxin pleurisy antibodies to rabbit [33].Thus, IL-8 appears to be an important cytokine in the development of acute pleural inflammation. Others have demonstrated that IL-1 $\beta$, TNF- $\alpha$, and LPS also cause expression of IL-8 messenger ribonuclie acid (mRNA) as tested via Northern-blot analysis in stimulated mesothelial cells (table 1).

In granulomatous diseases of the pleura, the pleural fluid consists primarily of mononuclear cells. In animal models of tuberculosis (TB) pleurisy, neutrophils are seen to predominate in the first $24 \mathrm{~h}$ following instillation of bacillus calmetteguerine (BCG) followed by large influx of macrophages [40].

\section{Table 1. - Pleural fluid cytokines}

\section{Infectious disease}

Interleukin-8 (IL-8)

Epithelial Neutrophil Activating Protein-78 (ENA-78)

Monocyte Chemotactic Protein-1 (MCP-1)

Macrophage Inflammatory Protein-1 $\alpha$ (MIP- $1 \alpha)$

Interleukin-1 $\alpha(\mathrm{IL}-1 \alpha)$

Interleukin-1 $\beta$ (IL-1 $\beta$ )

IL-1 Receptor Antagonist Protein

Interleukin-6 (IL-6)

Transforming Growth Factor- $\beta$ (TGF- $\beta$ )

Fibroblast Growth Factor (FGF)

Granulocyte-Monocyte Colony Stimulating Factor (GMCSF)

Insulin-Like Growth Factor-1 (IGF-1)

Endothelin-1 (ET-1)

Malignant disease

Plasminogen Activator Inhibitor-1 (PAI-1)

Endothelin-1 (ET-1)

Soluble ICAM-1

Platelet-Derived Growth Factor (PDGF)

Fibroblast Growth Factor $\beta$ (FGF $\beta$ )

Vascular Endothelial Growth Factor (VEGF)

Insulin-Like Growth Factor-1 (IGF-1)

Epidermal Growth Factor (EGF)

Hyaluron

Metalloproteinases (MMP)

Tissue Inhibitor of Metalloproteinases (TIMP)

Interleukin-6 (IL-6)

Interleukin-8 (IL-8)

Macrophage Inflammatory Protein- $1 \alpha($ MIP-1 $\alpha)$ 
A C-C chemokine, namely monocyte chemotactic protein (MCP)-1, has been found in large quantities in tuberculous pleural fluid. It is an $8.4 \mathrm{kD}$ protein member of the supergene family of C-C chemotactic cytokines [41]. Macrophage inflammatory protein (MIP)- $1 \alpha$ has also been found in pleural fluid from patients with TB pleurisy. In patients where there is a loss of immune function such as patients with acquired immune deficiency syndrome (AIDS), the level of both monocytes and specific monocyte chemokines are lower in patients who have pleural tuberculosis. IFN- $\gamma$ is an important proximal cytokine in the recruitment of mononuclear cells and is found in high quantities in pleural effusions of patients with TB pleurisy. The presence of IFN- $\gamma$ is consistent with previous reports that suggest that the T-helper cell type 1(Th1) subset of lymphocytes mediate the responses to mycobacterial infections [42]. When there is compartmentalisation of the CD4 cells in the pleural space, of patients with TB pleurisy, there is an increase in the amount of IFN- $\gamma$ production. Neutralisation of the IFN- $\gamma$ production causes abrogation of the local chemokine production by mesothelial cells and a decrease in the MIP-1 $\alpha$ and MCP-1 expression. Importantly, IL-4 causes a downregulation of the production of these chemokines.

\section{The mesothelium in malignant disease}

Understanding the pathogenesis of the disease process may help identify better management algorithms for these patients. The attachment of a malignant cell to the pleural mesothelium sets into play multiple factors that eventually result in the movement of the malignant cell through the pleural monolayer out into the pleural space. An example of malignant-cell interaction with the mesothelial cell is that of the interaction between hyaluron, a mesothelialcell derived extracellular matrix protein, and its CD44 receptor expressed by malignant cells with a predilection for the pleura [43-49]. Hyaluron is a high molecular-weight polymer composed of repeating saccharide units. It is known to be produced in large quantities by mesothelial cells. While high molecular-weight hyaluron remains a relatively inactive component, low molecular-weight hyaluron produced by hydrolysis of the high molecular-weight hyaluron is a very active protein fragment. Several cancer cells express a predilection for metastasis to the pleural surface. These include breast, ovary, lung, and stomach. Breast cancer cells express CD44 receptor and have a predilection for the pleural mesothelium. Addition of CD44 antibody to media blocks the adherence of malignant breast cancer cells to mesothelial monolayers [50]. Others have demonstrated that the hyaluron-CD44 complex is internalised into the malignant cell and undergoes hydrolysis via acid hydrolases. Hyaluron, which is a large molecular-weight component, is broken up into several small activated low-molecular weight fragments which can now participate in the process of transmigration of a malignant cell through the pleura. Thus, a gradient of hyaluron is set-up through the mesothelial monolayer. The malignant cell can now move from the basilar surface of the mesothelium to the apical surface into a hyaluronrich environment where it can establish itself and proliferate. Malignant cells are also known to produce large quantities of VEGF which changes the mesothelial monolayer permeability allowing for a protein-rich environment to be established on the apical surface of the pleura. This change in pleural permeability is also associated with malignant cell transmigration through the mesothelial monolayer. Tumour cells that produce fibroblast growth factor (FGF) can also affect their own ability to migrate and grow. In other studies, investigators have found suppression of metastasis formation in pleural colonisation by melanoma cells with blockage of CD44 receptors on malignant cells [51, 52]. Similar studies have been shown with pleural mesothelioma. Thus, it appears that one of the reasons why certain cancers have a predilection for the pleura may relate to their ability to express receptors for factors such as hyaluron which are produced in large quantities by the mesothelial cell. Once a malignant cell is established on the pleura, it produces factors such as VEGF and basic fibroblast growth factor (bFGF) to increase angiogenesis [53-55]. Angiogenesis is the process whereby new vessels emerge from existing endothelial-lined vessels. This is an invasive process that uses proteolysis of the extracellular matrix with proliferation and migration of endothelial cells. To achieve an adequate blood supply and further metastasise, the tumour cell produces factors that initiate the process of angiogenesis. Low molecular-weight hyaluron is angiogenic and can cause new endothelial sprouts and blood-vessel formation which increases its capacity to metastasise. It is important to realise that there are multiple factors that come into play at different stages of the metastatic cascade. These may have overlapping functions.

\section{Treatment of diseases of the pleura}

Treatments of diseases of the pleura exploit the underlying immunological mechanisms of pleural disease. In patients with empyema, fibrinolytic therapy has moderate success in selected patients and is useful in decreasing the complications of empyema. Fibrinolytic therapy is directed at inhibiting the coagulation cascade and allowing the newly formed fibrin to undergo fibrinolysis prior to the cellularisation of fibrin strands. When used at the appropriate time during the development of an empyema, resolution of a multiloculated pleural effusion can occur with minimal residual pleural fibrosis. In patients with malignant disease, attempts have been made to stimulate the intrapleural immune responses against invading malignant cells. In patients with malignant mesothelioma, IFN- $\gamma$ instillation was associated with some improvement, but was abandoned because of multiple sideeffects. Another form of therapy that is commonly used with patients with malignant disease is pleurodesis [56]. Among the sclerosing agents used are tetracycline, hydrochloride, doxycycline, and minocycline. However, talc has immerged as the most effective agent and has been studied both in vivo and in vitro [56-58]. In patients given talc, there is the rapid release of bFGF into the pleural space as measured in pleural fluid following talc insufflation. bFGF allows for an exuberant pleural fibrotic response to occur on the visceral and parietal pleura allowing for proliferation of fibroblasts and obliteration of the margins between the two pleural surfaces. It appears that the larger the surface area of normal mesothelial cells exposed to the talc, the higher the level of bFGF [59, 60]. This correlated with successful pleurodesis [61]. This also indicates that a vigorous response by normal pleural mesothelial cells, which are interspersed between the metastatic deposits, is critical for achieving pleural sclerosis. Thus, intimate approximation via adherence or phagocytosis of talc by mesothelial cells is important in the production of pleural sclerosis.

\section{References}

1. Wang NS. Anatomy and physiology of the pleural space. Clin Chest Med 1985; 6: 3-16. 
2. Harley R. Anatomy of the pleura. Semin Respir Med 1987; 9: $1-2$.

3. Davila RM, Crouch EC. Anatomic organization and function of the human pleura. Semin Respir Crit Care Med 1995; 16: 261-268.

4. Agostoni E, Miserocchi G, Bonanni MV. Thickness and pressure of the pleural liquid in some mammals. Respir Physiol 1969; 6: 245-256.

5. Albertine KH, Wiener-Kronish JP, Roos PJ, Staulo NC. Structure, blood supply, and lymphatic vessels of the sheep's visceral pleura. Am J Anat 1982; 165: 277-294.

6. Andrews PM, Porter KR. The ultrastructural morphology and possible functional significance of mesothelial microvilli. Anat Rec 1973; 177: 409-426.

7. Odor DL. Observations of the rat mesothelium with electron and phase microscopes. Am J Anat 1954; 95: 433.

8. Wheeldon EB, Mariassay AT. The pleura: A combined light microscopic, scanning, and transmission electron microscopic study in the sheep. II Response to injury. Exp Lung Res 1983; 5: 125-140.

9. Sahn SA. State of the art. The pleura. Am Rev Respir Dis 1988; 138: 184-234.

10. Light RE. Parapneumonic effusions and infections of the pleural space. In: Pleural Disease. 2nd edition. Philadelphia, Lea and Febiger, 1990; pp. 129-149.

11. Light RE, Erozan YS, Ball WC. Cells in pleural fluids and their value in differential diagnosis. Arch Intern Med 1973; 132: 854-860.

12. Collins JD, Disher AC, Shaver ML, Miller TQ. Imaging the hepatic lymphatics: Experimental studies in swine. $J$ Natl Med Assoc 1993; 85: 185-191.

13. Courtice FC, Simmonds WT. Physiological significance of lymph drainage of the serous cavities and lungs. Physiol Rev 1954; 34: 419.

14. Courtice FC, Morris B. The effect of diaphragmatic movement on the absorption of protein and of red blood cells from the pleural cavity. Australian J of Experimental Bio and Med Science 1953; 31: 227.

15. Gaudio E, Rendina EA, Pannarale L, Ricci C, Marinozzi G. Surface morphology of the human pleura: A scanning electron microscopic study. Chest 1988; 93: 149-153.

16. Shumko JZ, Feinberg RN, Shalvoy RM, DeFouw DO. Responses of rat pleural mesothelium to increased intrathoracic pressure. Exp Lung Res 1993; 19: 283-297.

17. Michailova KN. The serous membranes in the cat. Electron microscopic observations. Anat Anz 1996; 178: 413-424.

18. Madison LD, Bergstrom-Porter B, Torres AR, Shelton E. Regulation of surface topography of mouse peritoneal cells: Formation of microvilli and vesiculated pits on omental mesothelial cells by serum and other proteins. J Cell Bio 1979; 82: 783-797.

19. Wang NS. Mesothelial cells in situ. In: Chretien J, Bignon J, Hirsch A, eds. The pleura in health and disease. New York, Marcel Dekker, Inc., 1985; pp. 23-42.

20. Whitaker D, Papadimitriou JM, Walters MN-I. The mesothelium: A histochemical study of resting mesothelial cells. J Pathol 1980; 132: 273-284.

21. Whitaker D, Papadimitriou JM, Walters MN-I. The mesothelium: A cytochemical study of "activated" mesothelial cells. J Pathol 1982; 136: 169-179.

22. Whitaker D, Papadimitriou JM. Mesothelial healing: Morphological and kinetic investigations. J Pathol 1985; 145: 159-175.

23. Light RW, Rodriguez RM. Management of parapneumonic effusions. Clin Chest Med 1998; 19: 373-382.

24. Antony VB, Sahn SA, Mossman B, Gail DB, Kalica A. Pleural cell biology in health and disease. Am Rev Resp Dis 1992; 145: 1236-1239.

25. Antony VB. Cytokines in pleural disease. In: Nelson S, Martin T, eds. Cytokines in Pulmonary Infectious Disease: Pathogenesis and Therapeutic Strategies. New York, Marcel Dekker, Inc., 1998; pp. 123-136.
26. Krogel C, Antony VB. Immunobiology of pleural inflammation: Potential implications for pathogenesis, diagnosis, and therapy. Eur Respir J 1997; 10: 2411-2418.

27. Hott JW, Yu L, Antony VB. Role of VEGF in the formation of malignant pleural effusions. Am J Resp and Crit Care Med 1999; 159: A212.

28. Isner JM, Asahara T. Angiogenesis and vasculogenesis as therapeutic strategies for postnatal neovascularization. J Clin Invest 1999; 103: 1231-1236.

29. Broaddus VC, Herbert CA, Vitangcol RV, Hoeffel JM, Bernstein MS, Boylan AM. Interleukin- 8 is a major neutrophil chemotactic factor in pleural liquid of patients with empyema. Am Rev Respir Dis 1992; 146: 825-830.

30. Antony VB, Godbey SW, Holm KA, Hott JW, Burdick MD, Strieter RM. Mesothelial cell derived epithelial neutrophil activating protein-78 (ENA-78): A major neutrophil chemokine in parapneumonic effusions. Am J Respir Crit Care Med 1996; 153: A44.

31. Miller EJ, Idell S. Interleukin-8: An important neutrophil chemotaxin in some cases of exudative pleural effusions. Exp Lung Res 1993; 19: 589-601.

32. Strieter RM, Standiford TJ, Huffnagle GB, Colletti LM, Lukacs NW, Kunkel SL. "The good, the bad, and the ugly": The role of chemokines in models of human disease. J Immunol 1996; 3583-3586.

33. Broaddus VC, Boylan AM, Hoeffel JM, et al. Neutralization of IL-8 inhibits neutrophil influx in a rabbit model of endotoxin-induced pleurisy. J Immunol 1994; 156: 29602967.

34. Goodman RB, Wood RG, Martin TR, Hanson-Painton O, Kinasewitz GT. Cytokine-stimulated human mesothelial cells produce chemotactic activity for neutrophils including Nap-1/IL-8. J Immunol 1992; 148: 457-465.

35. Antony VB, Hott JW, Kunkel SL, Godbey SW, Burdick MD, Strieter RM. Pleural mesothelial cell expression of C-C (monocyte chemotactic peptide) and C-X-C (Interleukin-8) chemokines. Am J Respir Cell Mol Bio 1995; 12: 581-588.

36. Antony VA, Godbey SW, Kunkel SL, et al. Recruitment of inflammatory cells to the pleural space. Chemotactic cytokines, IL-8, and monocyte chemotactic peptide-1 in human pleural fluids. J Immunol 1993; 151: 7216-7223.

37. Del Maschio A, Zanetti A, Corada M, et al. Polymorphonuclear leukocyte adhesion triggers the disorganization of endothelial cell-to-cell adherens junctions. J Cell Bio 1996; 135: 497-510.

38. Takeichi M. Cadherins: A molecular family important in selective cell-cell adhesion. Annu Rev Biochem 1990; 59: 237252.

39. Takeichi M. Morphogenetic roles of classic adherins. Current Opinion in Cell Bio 1995; 7: 619-627.

40. Antony VB, Sahn SA, Antony AC, Repine JE. Bacillus calmette-guerine stimulated neutrophils release chemotaxins for monocytes in rabbit pleural spaces and in vitro. J Clin Invest 1985; 76: 1514-1521.

41. Kunkel SL, Chensue SW, Strieter RM, Lynch JP, Remick DG. Cellular and molecular aspects of granulomatous inflammation. Am J Respir Cell Mol Bio 1989; 1: 439-447.

42. Barnes PF, Fong SJ, Brenna PJ, Twomey PE, Mazumder A, Modlin RL. Local production of tumor necrosis factor and IFN- $\gamma$ in tuberculous pleuritis. J Immunol 1990; 145: 149154.

43. Jiang W. In vitro models of cancer invasion and metastasis: Recent developments. Eur J Surg Onc 1994; 20: 493-499.

44. Zetter B. Adhesions molecules in tumor metastasis. Semin Cancer Bio 1993; 4: 219-229.

45. Sneath RJS, Managham DC. The normal structure and function of CD44 and its role in neoplasia. J Clin Pathol 1998; 51: 191-200.

46. Koukoulis GK, Patriarca C, Gould VE. Adhesion molecules and tumor metastasis. Human Pathol 1998; 29: 889-891.

47. Trochon V, Mabilat C, Bertrand $\mathrm{P}$, et al. Evidence of involvement of CD44 in endothelial cell proliferation, 
migration, and angiogenesis in vitro. Int $J$ Cancer 1996; 66: $664-668$

48. Bourgignon L, Lokeshwar V, Chen X, Kerrick WG. Hyaluronic acid induced lymphocyte signal transduction and HA receptor (GP85/CD44)-cytoskeleton interaction. J Immunol 1993; 1551: 6634-6644.

49. Menzel EJ, Farr C. Hyaluronidase and its substrate hyaluronan: Biochemistry, biological activities, and therapeutic uses. Cancer Letters 1998; 131: 3-11.

50. Hott JW, Godbey SW, Antony VB. The role of the mesothelial cell in pleural metastasis: Inhibition of breast carcinoma cell adherence to pleural cells by hyaluronidase. FASEB J 1992; 6: A1919.

51. Seiter S, Arch R, Reber S, et al. Prevention of tumor metastasis formation by anti-variant CD44. J Exp Med 1993; 177: 443-455.

52. Hott JW, Yu L, Godbey SW, Holm KA, Antony VB. The role of the mesothelial cell in pleural metastasis; breast carcinoma cell proliferation in response to a pleural mesothelial cell derived growth factor. Am J Resp and Crit Care Med 1996; 153: A44.

53. Eliceiri BP, Cheresh DA. The role of $\alpha \mathrm{v}$ integrins during angiogenesis: Insights into potential mechanisms of action and clinical development. J of Clin Invest 1999; 103: 12271230 .
54. Stetler-Stevenson WG. Matrix metalloproteinases in angiogenesis: A moving target for therapeutic intervention. $J$ of Clin Invest 1999; 103: 1237-1241.

55. Ozer E, Canda T, Kurtoolu B. The role of angiogenesis, laminin, and CD44 expression in metastatic behavior of early-stage low-grade invasive breast carcinomas. Cancer Letters 1997; 122: 119-123.

56. Loddenkemper R. Thoracoscopy-state of the art. Eur Respir $J$ 1998; 11: 213-221.

57. Bethune N. Pleural poudrage: A new technique for the deliberate production of pleural adhesions as a preliminary lobectomy. J Thorac Curg 1935; 4: 251-261.

58. Rodriguez-Panadero F, Antony VB. Pleurodesis: State of the art. Eur Respir J 1997; 10: 1648-1654.

59. Nasreen N, Hartman DL, Mohammed KA, Antony VB. Talc-induced expression of C-C and C-X-C chemokines and intercellular adhesion molecule-1 in mesothelial cells. Am J Resp Crit Care Med 1998; 158: 971-978.

60. Antony VB, Mohammed KA, Godbey S, Loddenkemper FW. Talc-induced pleurodesis: Role of basic fibroblast growth factor (bFGF). Eur Respir J 1997; 10: A403.

61. Rodriguez-Panadero F, Segado A, Juan JM, Ayerbe R, Garcia IT, Castillo J. Failure of talc pleurodesis is associated with increased pleural fibrinolysis. Am J Resp and Crit Care Med 1995; 151: 785-790. 